\title{
Word order, referential expression, and case cues to the acquisition of transitive sentences in Italian
}

Article

Accepted Version

Abbot-Smith, K. and Serratrice, L. (2015) Word order, referential expression, and case cues to the acquisition of transitive sentences in Italian. Journal of Child Language, 42 (1). pp. 1-31. ISSN 0305-0009 doi:

https://doi.org/10.1017/S0305000913000421 Available at https://centaur.reading.ac.uk/66678/

It is advisable to refer to the publisher's version if you intend to cite from the work. See Guidance on citing.

Published version at: http://dx.doi.org/10.1017/S0305000913000421

To link to this article DOI: http://dx.doi.org/10.1017/S0305000913000421

Publisher: Cambridge University Press

All outputs in CentAUR are protected by Intellectual Property Rights law, including copyright law. Copyright and IPR is retained by the creators or other copyright holders. Terms and conditions for use of this material are defined in the End User Agreement.

www.reading.ac.uk/centaur 
Central Archive at the University of Reading

Reading's research outputs online 


\title{
Word order, referential expression, and case cues
}

\section{to the acquisition of transitive sentences in Italian}

\author{
Kirsten Abbot-Smith ${ }^{1}$ and Ludovica Serratrice ${ }^{2}$ \\ ${ }^{1}$ School of Psychology, University of Kent, UK \\ ${ }^{2}$ School of Psychological Sciences, University of Manchester, UK
}

Please send correspondence to: Kirsten Abbot-Smith

School of Psychology,

University of Kent,

Keynes College

Canterbury CT2 7NP, UK

Email: K.Abbot-Smith@kent.ac.uk

Acknowledgements: Many thanks to Prof. Chiara Cantiani for collecting the data, coding the standardised language sub-test, for having such a wonderful rapport with both children and nursery staff ; to Dr. Francesca Foppolo and Prof. Maria-Teresa Guasti for help in setting up the study; to Gianluca Marvulli for editing the video and audio clips and for coding the Marco corpus; to Dr. Francesca Roncarati for pointing coding reliabilities; to Samantha Durrant for scoring the MacArthur questionnaires; and especially to Anthony Mee at the University of Plymouth for writing such a wonderful stimuli presentation programme, and to Caroline Rowland, the anonymous reviewers and especially to the action editor for such detailed comments. A big thanks also to all the parents, children and 'maestre' at the following nurseries: Micronido Capiago, Allegra Brigata, Le coccinelle, Asilo nido "Magolibero", L'aquilone, Marialuisa, Primi Passi, Cislaghi, micronido "Arcobaleno", asilo nido "la girandola", Scuola materna "Gianetti", C.R.D. Valmadrera, C.R.D. ERBA, Scuola materna Buccinigo, and Scuola dell'infanzia "San Pio X". This work was funded by a British Academy Small Grant SG46233 to the first author. A poster of this study was presented at the $16^{\text {th }}$ annual conference on the Architectures and Mechanisms of Language Processing on $6^{\text {th }}$ September 2010 and it was also presented at the $12^{\text {th }}$ conference of the Association for the Study of Child Language in Montreal thanks to a BA travel grant to the first author 


\section{ABSTRACT}

In Study 1 we analysed Italian child-directed-speech (CDS) and selected the three most frequent active transitive sentence frames used with overt subjects. In Study 2 we experimentally investigated how Italian-speaking 2;6, 3;6 and 4;6-year-olds comprehended these orders with novel verbs when the cues of animacy, gender and subject-verb agreement were neutralised. For each trial, children chose between two videos (e.g. horse acting on cat versus cat acting on horse), both involving the same action. The 2;6-year-olds comprehended $\mathrm{S}+$ object-pronoun $+\mathrm{V}$ significantly better than the $\mathrm{S}+\mathrm{V}+$ object noun sentences. We explain this in terms of cue collaboration between a low cost cue (case) and the 'first argument $=$ agent cue' which we found to be reliable $76 \%$ of the time. The most difficult word order for all age groups was the object-pronoun $+\mathrm{V}+\mathrm{S}$. We ascribe this difficulty to cue conflict between the two most frequent transitive frames found in CDS, namely ' $\mathrm{V}+$ object-noun' and 'object-pronoun+V'. 
INTRODUCTION

Over the last thirty years a great deal of attention has been devoted to the study of children's comprehension of the transitive construction, both in its active (e.g. The dog chased the cat) and its passive form (e.g. The cat was chased by the dog). The focus on these two sentence frames or constructions encapsulates a more wide-ranging debate over the degree to which syntactic acquisition can be accounted for by initial heuristics such as 'map the first noun of the sentence onto the agent (e.g. Bates and MacWhinney, 1982) as opposed to generic mechanisms, such as those which calculate transitional probabilities (Mintz, 2003).

Regarding higher-level heuristics, one claim with quite a long history is that children may be initially biased to interpret the first argument they encounter in a sentence as being the agent of an action (e.g. Bever, 1970; de Villiers \& de Villiers, 1973; Bates \& MacWhinney, 1982). Certainly, English-speaking children seem to rely on word order in comprehending active transitive sentences containing a novel verb - at least for causal actions - at 2;3 when asked to point, and at 1;9 when they just have to look at the correct novel event out of two when they hear e.g. 'the duck is gorping the bunny' (e.g. Gertner, Fisher \& Eisengart, 2006; Noble, Rowland \& Pine, 2011).

The same strategy may not be as successful in languages where there is pervasive argument ellipsis and/or word order is more flexible, such as Russian, or in languages, which have no preferred word order (Austin, 1992). In languages which allow a number of word order variants, the primary means of marking grammatical roles is typically via morphological means such as case-marking or subject-verb agreement.

Within the first language acquisition literature, the only framework which has really attempted to determine which morphological and syntactic markers, or cues, children are most sensitive to has been the Competition Model (e.g. Bates \& MacWhinney, 1987) although early work by Slobin and colleagues took a similar approach (e.g. Slobin \& Bever, 1982) and more recently Matessa and Anderson (2000) have combined the ACT-R framework with the Competition Model to address 
essentially the same issue. All of these approaches have focussed on 'form-function' mappings, by which they attempt to predict the relative weight which a listener or learner will give various potential cues (e.g. word order, case, animacy) to the agent and patient roles (i.e. they implicitly assume the direct mapping of form onto semantic roles without intervening syntactic roles - and notably they only do so with regard to sentences with causative verbs, since only these have agent and patient roles). The Competition Model is especially useful as attempts have been made to quantify the validity of various cues to these semantic roles with the transitive construction in a manner that can be applied crosslinguistically. Two measures which have been argued to be particularly relevant for child language acquisition are cue reliability and cue validity.

\section{Cue reliability and cue validity}

A cue is deemed 'reliable' when it indicates a particular function (as opposed to another function) all or most of the time. Cue validity is a product of cue reliability and cue availability (i.e. the input frequency of a particular grammatical marker). One of the earliest papers from the Competition Model framework made the case that cue validity is a key determinant of the degree to which children will follow a particular cue when comprehending sentences. To elaborate: Bates, MacWhinney, Caselli, Devescovi, Natale \& Venza (1984) found that Italian two-year-olds, for example, rely on animacy over word order as a cue to the agent, whereas English-speaking two-year-olds do the reverse, at least with familiar verbs. Their argument was that this is because pre-verb word order position has extremely high cue validity to the agent in English, but not in Italian where subjects/agents tend to be omitted most of the time and agent subjects can appear after the verb when they express focused new information.. Other Competition Model theorists have, however, presented evidence that while cue validity may be crucial early in acquisition, later on it is cue reliability that determines which cue is most likely to be followed (e.g. Sokolov, 1988). In effect, the latter argument is that the availability of a cue in a 
particular language environment may determine how quickly a particular cue is learnt, but once it has been learnt, the most reliable cue will be the one that is most closely followed upon.

\section{Cue cost}

Cue validity calculations do not take account of the fact that different cues might pose more inherent difficulty to a learner than others. That is, many Competition Model theorists have argued that some cues might be higher in 'cue cost', defined as a function of the perceptual salience of the cue and the burden it places on working memory (Kempe \& MacWhinney, 1999). The notion of cue cost is based on the distinction between local and topological processing as originally proposed by Ammon \& Slobin (1979). The idea is that cue cost is lowest for processing that takes place at the level of the single word and that it increases as a function of the distance between elements that need to be processed in relation to one another. The distinction between local and topological cues should therefore be treated as more of a continuum than a dichotomy. The cost for cues like gender, number or case that are directly and locally marked by inflections on lexical items is low as processing takes place as soon as the relevant marker on the word is encountered. The syntactic cue that has frequently been argued to be lowest in 'cue cost' is case-marking, as this can be processed locally without reliance on short-term memory (see also Slobin's, 1982, ‘local cues' proposal). There is indeed some evidence that children learning languages like Turkish, in which semantic roles are primarily marked by case, do successfully comprehend who is doing what in transitive sentences much earlier than children learning predominately word-order languages, such as English (e.g. Slobin \& Bever, 1982). Turkish preschool children are also more likely to enact a transitive sentence in a causal manner if the accusative case marker is present (e.g. Göksun, Küntay, \& Naigles 2008). Linear word order is also considered to be low in cue cost when words that need to be processed in relation to one another are adjacent, but it is not as low as case-marking which is marked on a lexical item itself (e.g. 'him'); for the latter, the semantic role can be processed without any reference to other words in the sentence. 


\section{Cue competition}

Another issue is cue competition; depending on the relative overall validity of two cues (e.g. case and word order), a less reliable but more available cue might hinder the acquisition of the more reliable but less available cue. Dittmar, Abbot-Smith, Lieven \& Tomasello (2008) investigated this possibility with German-speaking children, using both act-out (Study 2) and a pointing task (Study 3), in both cases with novel verbs. Preschool children were tested on three transitive frames which occur in German CDS: SVO / SOV with case-marked arguments, SVO / SOV without case-marking and OVS / OSV with case-marked arguments. Case-marking was found to have higher validity (86\%) in CDS, than the validity of the subject-before-object word order cue $(68 \%)$ and this explains why SVO/SOV with case-marking was comprehended earlier in development than SVO / SOV without case-marking. However, it was not until the age of 7 years that German children pointed significantly above chance for the (case-marked) OVS sentences, which the authors explain in terms of cue conflict / competition between case-marking and word order. Certainly, findings on adult processing show that any type of competition between cues results in slower reaction times (e.g. McDonald \& MacWhinney, 1995).

\section{Information structure and the acquisition of the transitive construction}

Both the proposed 'first argument=agent' (or first-of-two-nouns) heuristic, on the one hand, and the Competition Model factors of cue validity, cost and competition (although not reliability), on the other - meet a potential stumbling block in the face of languages with pervasive subject ellipsis. Interestingly, argument ellipsis, which is grammatically permissible in many languages, in many ways parallels which transitive sentence arguments are typically lexicalised versus pronominalised in languages that do not allow argument ellipsis. Du Bois (1987) was one of the earliest linguists to propose this parallel and to establish that transitive subjects (or ' $A$ ' if we are to include ergative languages) are much less likely to occur as nouns than intransitive subjects (' $\mathrm{S}$ ') or transitive objects 
('P'). The preferred argument structure in languages with argument ellipsis tends to be for the transitive subject to be omitted and the preferred argument structure in languages that do not permit argument ellipsis tends to be for the transitive subject to be pronominalised (du Bois, 1987). At first sight, the most logical assumption would appear to be that when children are learning their first language, they would find it easier to map the transitive object onto its referent since this is much more likely to be lexicalised. However, this would only be true if the transitive sentence occurred in isolation. In fact, transitive sentences occur as part of discourse in which the transitive subject can often be assumed as it is most likely to be the 'given' rather than the 'new' element of the discourse (du Bois, 1987).

It is now well established that young two-year-olds are adept at determining which elements of their interactions with their parents are 'given' versus ' new' (e.g. Tomasello \& Akthar, 1995) and hence in reality most of the time in naturalistic CDS the omitted or pronominalised argument is not ambiguous in terms of its referent. Indeed, if the child is adept at tracking referents through discourse, then a case-marked pronoun in a sentence might actually be very easy to process and map onto its referent, if its antecedent is known. If a transitive sentence occurs outside of a discourse context, however, then lexicalised subjects and objects will be easier to map onto the real-world referents. This may account for why in experimental contexts young preschool children find it easier to map novel words onto actions when these co-occur with nouns than when they co-occur with pronouns (e.g. Arunchalam \& Waxman, 2011; see also Naigles, Reynolds \& Kuntay, 2011).

\section{Italian}

We chose to study children's comprehension of causal action transitive sentences in Italian because it is a language with case (on pronouns), in which subjects are omitted around $74 \%$ of the time (e.g. Lorusso, Caprin \& Guasti, 2005) When the grammatical subject is not omitted, it can follow the verb (e.g. Lorusso et al., 2005) if it is associated with new information in focus. This is pragmatically constrained as the position following the verb is associated with 'new' information to the discourse. For 
example, in response to a question like 'Who ate the cake' (to which the answer is 'Laura'), the typical Italian response would be (1) (see Pinto, 1997).

$\begin{array}{lll}\text { (1) L' } & \text { ha } & \text { mangi-at-a Laura } \\ \text { it;ACC-SG } & \text { auxiliary;3SG } & \text { eat-PRF-F.SG Laura } \\ \text { 'Laura ate it.' } & & \end{array}$

A particularity of Italian concerns the interaction between word order, type of referential expression and case marking. While both subject pronouns and full subject NPs can appear before and after the verb, the word order position of grammatical objects in Italian is determined by the type of referring expression. Pronominal objects (which are systematically and unambiguously case-marked, see Appendix A) have to occur immediately before the verb (except in certain modal constructions and in imperatives). Full object NPs are not case-marked and predominately occur after the verb. These facts have not been taken into account in the Competition Model literature on the acquisition of Italian and French. Rather, children (and adults) have been presented with sentences with NOUN-NOUN-VERB (NNV) orderings despite the fact that such sentences are extremely rare (or indeed ungrammatical) in standard Italian (e.g. Bates et al., 1984; Devescovi, d'Amico \& Gentile,, 1999; d'Amico \& Devescovi, 1993; MacWhinney, Bates \& Kliegl, 1984).

Furthermore, although 'object-pronoun+verb+subject'(OPROVS) occurs in Italian, Italian adults have a strong bias to interpret NVN sentences as SVO if there is no imbalance in animacy or prosody, and if subject-verb agreement does not lead the listener to prefer one noun phrase over the other as agent (e.g. if both subject and object are third person singular). For NVN sentences adult participants have been found to choose the first noun as agent over $85 \%$ of the time in Bates et al. (1984). Even Italian 4;6-year-olds have been found to choose this interpretation in $70 \%$ of their act-out responses with familiar verbs (d'Amico \& Devescovi, 1993). 
The present study

We thus conducted two studies to investigate which cues are used to understand causative transitive sentences by young pre-school children learning Italian. In Study 1 we carried out the largest corpus analysis of Italian CDS to date using the Tonelli (Tonelli \& Fabris, 2005) and Calambrone (Cipriani, Pfanner, Chilosi, Cittadoni, Ciuti, Maccari, Pantano, Pfanner, Poli, Sarno, Bottari, Cappelli, Colombo \& Veneziano, 1989) corpora. Our first aim was to calculate cue reliabilities and validities for both agents and patients for word order and case (over all transitives - both with overt and non-overt subjects) in Italian CDS. This analysis allowed us to establish what kinds of transitive sentences Italianspeaking children are actually likely to hear in terms of the number of expressed arguments (both the subject and the object as opposed to only the object), word order with respect to the verb (the distribution of pre- and post-verbal subjects, pre- and post-verbal objects), and the form of the referential expressions used to realize arguments (full NPs, e.g. il gatto, as opposed to pronouns, e.g. lui/lo). Our results from Study 1 generated our cue reliability and cue validity based hypotheses for Study 2 .

Study 2 used a pointing paradigm identical to that previously used by Dittmar et al. (2008: Study 3). That is, the comprehension of transitive sentence frames was tested using novel verbs, whereby the child was asked which video clip (target vs. distractor) matched the sentence the experimenter used. The two novel actions were identical in both target and distractor clips and the same two animals (e.g. cow and frog) occurred in both the target and distractor clips - the only difference was which animal mapped onto the agent vs. patient role. To illustrate, if a child heard a particular test sentence containing for example the novel verb and the Italian word for 'cow', the child would not be able to use this information alone to work out which video clip was meant because both video clips contained cows. Rather, the child would need to be able to utilise his or her knowledge of morphosyntax (specifically word order and / or case-marking) to determine which video clip was the correct one. For each individual trial, the grammatical gender of the animals was always identical so that reference 
could not be determined based on gender. Thus, our second aim was simply to investigate at which age Italian children would understand basic active transitive sentences with causative novel verbs, but without animacy and subject-verb agreement cues. We therefore chose the three word orders that are most frequently used with Italian declarative transitive sentences, when those sentences do have an overt subject. These word orders are SVO, SOV and OVS and are illustrated in (2)-(4) below (see also Appendix B). The first, SVO (with two full NPS) allows us to indirectly compare our results with those of the German-speaking and English-speaking children who had previously been tested with this method using identical novel actions (see Dittmar et al., 2008: Study 3 for German; Dittmar et al., 2011, for English)

(2) SUBJECT + VERB + OBJECT-NOUN (SVONOUN)

Il gatto baff-a il cavallo

the; $\mathrm{M}$ cat baff-PRS;3SG the;M horse

'The cat is baffing the horse.'

(3) SUBJECT + OBJECT-PROUN + VERB (SOPROV)

Il gatto 1-o baff-a

the;M cat it;ACC-M;SG baff-PRS;3SG

'The cat is baffing it.'

(4) OBJECT-PROUN + VERB +SUBJECT (OPROVS)

L-o baff-a il gatto

it;ACC-M;SG baff-PRS;3SG the;M cat

'The cat is baffing it.' 
Thus, one key research question was whether Italian-speaking children would comprehend SVO word order (i.e. sentences such as (2)) later than German- and English-speaking children simply because of the pervasive subject ellipsis in Italian. We also investigated the following research questions in Study 2.

\section{H1 Mappability: SVONOUN will be easier to acquire / comprehend than either the SOPROV or}

the OPROVS frame. From an 'ease of mapping' point of view (e.g. Arunchalam \& Waxman, 2011), one would predict that Italian children should perform better in the subject+verb+object-noun (SVONOUN) condition (see (2)) than in the other two conditions. This is because the SVONOUN condition contains two full NPS and thus has twice the mappability of the other two conditions in which the referents of the pronouns can only be determined once the NP-subject has been mapped onto its referent.

H2 Information structure: OPROVS > SOPROV. From an information-structure perspective one would predict better performance in the OPROVS (see (3)) than in the SOPROV (see (2)) condition. Both of these conditions are pragmatically a little odd in the context of our experiment as the grammatical objects are pronominalised even though they have no discourse antecedents. However, given that the post-verb position is the position for 'new' information in Italian (Pinto, 1997) and that new information tends to be lexicalised (du Bois, 1987), a lexicalised post-verbal subject is more in line with Italian information structure constraints when it co-occurs with a pronominalised object. Furthermore, because we adopted the paradigm used by Dittmar et al. $(2008,2001)$ in which the action was the same in both the target and the distractor scenes, the subject is more appropriate in the postverbal (new information) position (as in (3)) since the subject is different in the two scenes that the child is asked to choose between. 
We also aimed to investigate factors purported by Competition Model theorists to play a role in how children learn to comprehend transitive sentences, namely cue reliabilities, validities, cue cost and cue competition.

H3 Cue cost / local cues: (SOPROV, OPROVS) . SVONOUN. From the point of view of cue cost or local cues, the conditions with case-marking (see (2) and (3)) should be easier than the condition without (see (1). In regard to cue cost, the way in which case is marked on Italian pronouns means that it should be particularly easy to learn, especially on the third person singular accusative forms ' $l o$ ', ' $l a$ ' and ' $l$ ' (which are the forms we chose for our test sentences), since these have no other function within the pronoun system (unlike German, for example, see Appendix A). 'Lo' is low in overall frequency since it can only be an accusative masculine pronoun. The same is true for 'la' as a feminine accusative pronoun but it also has a homophone which is the feminine definite article.

H4 Cue conflict: (SVONOUN, SOPROV) > OPROVS. Regarding cue competition / conflict we predicted that the 'OPROVS' (OPROVS) frame would be particularly difficult to comprehend / acquire since it constitutes a clash between these two predominant (subjectless) frames: 'VERB+-object-noun' $($ VONOUN) and 'object-pronoun+VERB' (OPROV).

H5 Cue collaboration: Sop > (SVONOUN, OPROVS) Regarding 'cue collaboration'our prediction is that 'SUBJECT+ object-pronoun $+V E R B$ ' $(S O P R O V)$ should be the easiest to comprehend as here the low-cost case cue collaborates with the (non-conflicting) 'first argument = agent' cue.

\section{STUDY 1}

\section{Corpus details}

Our data come from the Tonelli (Tonelli \& Fabris, 2005) and Calambrone (Cipriani et al., 1989) corpora, which are dyadic corpora of naturalistic interaction between Italian mothers and their children. 
The Tonelli corpus is the only corpus of Italian child language on the CHILDES database (see www.childes.psy.cmu.edu, MacWhinney, 2000) which has been MORed (that is, tagged according to grammatical categories of individual words). There are five untagged Italian child language corpora on CHILDES and we selected parts of one of these, the Calabrome corpus because it had already been partially coded by the second author and, at the time of writing, one child's data, Diana, had also been morphologically tagged. Details of these corpora are given in Table 1.

TABLE 1 HERE: Details of the Italian child-directed maternal speech corpora

\section{Corpus coding procedure}

Following previous Competition Model studies, our analysis focused on the structure of simple declarative transitive clauses. Therefore, before coding, we excluded all utterances that did not contain verbs. From the utterances containing verbs, we also excluded several types that were not relevant to the analysis. First, we excluded all relative clauses and questions because these structures have different word orders from simple declarative sentences. Second, we excluded all imperatives because subjects are usually omitted in imperatives. Third, we excluded all intransitives because they never have objects by definition. Fourth, we excluded all material in stories, direct quotes, songs, rhymes, and idioms because they often contain fixed forms or non-standard wording (e.g. to facilitate a rhyme or fulfill a particular meter pattern) that do not mirror the structure in simple transitive clauses. If an utterance had two codable clauses (either through conjunction or embedding), it was divided into two and both were coded. Details of the original numbers of maternal utterances in the corpora and the number of declarative transitive utterances within these are given in Table 1. Data were selected from the unMORed Calambrone corpora in a slightly different manner: the second author randomly chose one transcript each for 4 MLUw stages of the child $(1.5-2.0 ; 2.0-3.0 ; 3.0-4.0 ;>4.0)$. Coding started from line 30 onwards in the script with the first utterance containing a lexical verb (which was not part of a story or rhyme). For each file at the four MLUw stages, the following 24 maternal utterances 
containing a lexical verb were included, resulting in a selection of 100 maternal utterances per child, these were then coded for whether they were declarative transitives or not following the aforementioned criteria used for the MORed corpora.

As can be seen on Table 1, on average $91-95 \%$ of the maternal utterances in the MORed corpora were excluded from further analysis; that is, only around 5-9\% of maternal speech directed at Italian one- and two-year-olds was found to have the form of a declarative transitive, which is very close to the proportion found for English (e.g. Cameron-Faulkner, Lieven \& Tomasello, 2003; Wells, 1981), primarily because the majority of utterances directed at Western middle-class children this age consist of either one or two words, or are questions, imperatives or copulas used in labeling contexts.

\section{Reliabilities}

The declarative transitive utterances (final column in Table 1 above) were coded by a native Italianspeaking linguistics graduate. The second author also independently coded $25 \%$ of these utterances with $92 \%$ agreement between the two coders. The disagreements all involved the coding of pronouns such as 'nulla' (=nothing) and 'uno' (one) or the inclusion of utterances which are idioms (e.g. 'fa la nanna' = lit. 'do the snoozy' = "sleeps"). Following this coding check, the first author systematically re-coded utterances involving these two issues accordingly..

\section{Results for construction or sentence frame frequencies:}

Our first question regarding the Italian CDS was the relative input frequency of transitive sentence frames with an overt subject; that is, is SVONOUN more frequent than SOPROV' or 'OPROVS'? Table 2 shows the percentage of each transitive frame out of all 1624 transitives (across all mothers). Crucial to our understanding of how Italian children learn to understand transitive sentences is our finding that of the total number of transitive sentences (all verbs, both causative and non-causative), on average only $17 \%$ contained both an overt subject and an overt object (see third column on Table 2), which is a 
similar degree of pro-drop to that found in the previous literature (Serratrice, 2005; Lorusso et al., 2005). Transitive sentences with subject ellipsis were overwhelming either of the form VONOUN or of the form OPROV (see the second to last column on Table 2 ). On average only $6 \%$ of the maternal declarative utterances had subject ellipsis and were also neither of the VONOUN or OPROV form. These included sentences with object clitics on the infinitive (in sentences with modal verbs, see (8)) and sentences with non-case-marked pronouns following the verb, which could in principle have been coded as nouns, as the meanings were almost always things like 'something', 'everything', 'one', 'nothing'.

TABLE 2 HERE: Formal characteristics of declarative transitive utterances by mother

\section{Summary of results for constructional frames}

With overt subjects: In sum, of our total corpora of maternal declarative transitives with overt subjects, 53\% involved the 'SVONOUN' frame; $21 \%$ involved 'SOPROV' frame, 14\% involved 'OPROVS frame', 3\% involved VOS (see e.g. 4) and 9\% involved VSO (see (5). The input examined never included NVN with OVS meaning nor NNV. With subject ellipsis: When the Italian mothers used transitives without an overt subject, the construction used was almost always either ' $\operatorname{VONOUN}$ (as in (6)' or 'OPROV' (as in (7). In the case, of 'OPROV' the pronoun was the third person pronoun, lo, $l a, l '$, (singular) or $l i$ or $l e$ (plural) $81 \%$ of the time.

(5) Uhi ha perso la lingua quest-o bimb-o Pfffff auxiliary;3SG lose;PRF the; F tongue this-M child-M 'puh! This child has lost his tongue!' (exclamatory) (to Marco, 1;10)

(6) no, adesso faccio

io un-a pistola

di carta 
No, now make;PRS.1SG I a-F gun paper

'No, now I'll be the one who'll make a gun out of paper'. (to Marco 2;1)

(7) mangi-a $\quad 1$ erba

eat-PRS;3SG the grass

'It/He//She eats / is eating (the) grass.' (to Marco $1 ; 8$ )

(8) l' hai rotto

it;ACC;SG auxiliary;2SG break;PRF

'You broke it.' (to Marco 1;9)

(9) sì ma adesso non vol-ev-o ved-er=lo

yes but now not want-PST-1SG see-INF=it-ACC.M.SG

'Yes, but now I didn't want to see it / him.' (to Marco 2;3)

\section{Cue reliabilities and validities}

Our second input-based analysis followed the Competition Model tradition of calculating cue reliabilities and validities across all of these sentence types. Here we follow the formula used by Kempe and MacWhinney (1998) and Dittmar et al. (2008). Our denominator for each analyses is the pool of both overt subject AND subjectless transitives, because subjectless transitives are clearly predominant in the input and - as we saw above - are clearly 'sub-units' of the overt subject transitives. Moreover, from a sentence processing perspective, a listener cannot be sure when processing an 'OPROV' transitive frame whether this is in fact going to end up being an 'OPROVS' transitive frame. 
Traditionally, Competition Model studies calculate the validity of cues indicating the agent. We first calculated this and then cue validity analyses for cues indicating the patient because of pervasive subject ellipsis in the language. Since agents and patients only occur with causal action verbs, the following analyses presented below only include the total number of causative verb transitive sentences as our denominator. (However almost identical results were found when we included all transitive verb declarative sentences). Thus 'cue availability' was the number of sentences in which a cue is present out of the total number of transitive sentences containing causal action verbs with or without an overt subject. 'Cue reliability' was the number of sentences in which a cue correctly indicated the particular semantic role, divided by the number of transitive sentences containing causal action verbs in which the cue was present. Finally, to calculate 'cue validity', we multiplied 'availability' and 'reliability'.

Results for cue validities for the 'agent':

Previous Competition Model studies have defined word order cues to the agent as either "first noun of sentence" (e.g. Kempe \& MacWhinney, 1998; Dittmar et al., 2008) or "noun before the verb" (Kempe \& MacWhinney, 1998) or have not provided a definition (e.g. Bates et al., 1984) We analysed 'word order' cues validities to the 'agent' in three different ways: "First of two arguments" (=processing of linear word order of two arguments (including both nouns and pronouns) within the transitive sentence relative to one another); "Argument before verb" and "Noun before verb" (both of which compute word order with respect to adjacency to the verb.

To illustrate, the cue validity of the cue of "the $1^{\text {st }}$ of 2 arguments"' as a cue to the agent was calculated as follows:

a) The availability for the cue " 1 st of 2 arguments" is the sum of all transitives with causative verbs with TWO arguments, whether pronominal or lexical, (i.e. all SVONOUN, SOPROV, OPROVS, VSO, 
VOS etc) divided by all the transitive sentences (whether full transitives or transitives with argument ellipsis) containing causative verbs

b) Reliability is the sum of all 2-argument causative transitive in which the subject precedes the object (i.e. SVONOUN+SOPROV+VSO) divided by the sum of all transitives with causative verbs with TWO arguments, whether pronominal or lexical, (i.e. all SVONOUN, Sop+V, OPROVS, VSO, VOS etc).

c) The validity is simply a) availability $\mathrm{x}$ b) reliability

Cue reliability: Cue reliability for 'first of two arguments' was 76\%. Cue reliability for 'noun directly before verb' was even higher (83\%). (Note that it is not perfect as some 'object-noun+VERB' (onV) sentences such as (10) below were found in the input). Cue reliability for 'argument directly before verb' was low, only 19\%, because object-pronouns were frequently found in this position, both in SOPROV' sentences such as (9) below and in 'OPROV' sentences such as (7). The cue reliability of nominative case-marking is by definition $100 \%$ but case-marked nominatives (see e.g. (11)) were extremely rare as ellipsis is preferred.

(10) Il bimb-o lo port-a dentro the;M child-M it;ACC.M.SG carry-PRS;3SG inside 'The boy is carrying it inside.' (to Elisa 1;10)

$\begin{array}{llrlr}\text { (11) un } & \text { pezzetto di } & \text { sasso abbiamo } & \text { aggiunto } \\ \text { a;M } & \text { piece of } & \text { stone } & \text { auxiliary;PRS.1PL } & \text { added_on;PRF }\end{array}$ 'We have added on a piece of stone.' (to Marco 2;1) 
(12)
lo
prend-o
io
it;ACC-M;SG
get-PRS;1SG
I

'I'll get it.' (to Marco 2;4)

(13)

$\begin{array}{lllll}\text { l' } & \text { ha } & \text { presa } & \text { la } & \text { Giuliana } \\ \text { it;ACC;SG auxiliary;3SG } & \text { take;PRF.F } & \text { the;F } & \text { Giuliana } \\ \text { 'Giuliana took it.' (to Marco 1;5) } & & & \end{array}$

Cue validity: We found that cue validity was extremely low for all potential word order cues to the 'agent'; the highest was $15 \%$ for 'the first of two arguments' (cf. $68 \%$ for word order and $86 \%$ for case in German, Dittmar et al., 2008: Study 1). The validity of case marking as a cue to the agent was also very low, only $6 \%$, due to the preference for subject ellipsis over subject pronouns in Italian. low.

Results for cue validities for the 'patient':

Given the very low availability (and hence potentially low informative value) of cues to the agent, our next analysis examined the relative validities of cues indicating the patient in Italian CDS.

Word order(not taking type of referring expression into account): In previous Competition Model studies, the cue validity of word order has been measured without taking into account the type of referential expression. Figure 1 below reports this analysis, showing the relative validity of pre-verbal versus post-verbal position as well as accusative case as a cue to the patient. To illustrate, when calculating the reliability of 'verb+argument' (i.e. sentences in which the verb is followed directly by either a noun or pronoun or pronominal clitic) as a cue to the patient, VSO sentences such as that in (5) and OPROVS sentences (see 11 and 12) would lower the reliability). 
FIGURE 1 HERE: Word order and case cue validities for cues for the patient (not taking type of referring expression into account).

Word order taking into account the type of referential expression: Figure 2 below calculates the "VONOUN" cue - verb followed by a noun - which is quite a bit more reliable than simply 'verb+argument' as a cue to the patient (as sentences with pronominal subjects in post-verb position as in (11) above, are no longer considered as part of the denominator). (Note that the $\mathrm{V}+\mathrm{N}$ bars on Figure 2 below are a subset of the Verb+argument bars on Figure 1). A similar phenomenon is observed when comparing cue validity of 'case-marked pronoun $+V$ ' (Fig 2) with 'argument $+V$ ' (Fig 1) as cues to the patient. (Note that the set of 'accusative-case-marked pronoun before verb' bars on Figure 2 below are a sub-set of both the 'argument+verb' and the 'accusative case' bars in Figure 1).

FIGURE 2 HERE: Slot and frame type cue validities.

\section{Discussion}

Our corpus analyses reveal a high degree of regularity in terms of how word order marks grammatical and semantic roles in transitive sentences in Italian CDS. The cue reliability of verb+noun as a cue to the patient is $97 \%$ and the cue reliability of noun+verb as a cue to the agent is $83 \%$. This explains why Italian adults almost invariability interpret $\mathrm{NVN}$ as SVO when animacy and subject-verb agreement are neutralised (e.g. Bates et al., 1984). A key feature of Italian CDS is the high degree of subject ellipsis. Thus, the availability (and hence validity) of word order cues to the agent is very low which leads to the prediction that Italian children should comprehend SVO later than their English- or Germanspeaking counterparts. However, following the findings of Sokolov (1988), one might predict that the reliability of cues to the agent would play an important role in sentence comprehension later on in child development. 
In terms of cues to the patient, our analyses for cue validities for the patient do not result in any clear predictions pertaining to word order or case cues, basically because the 'object-pronoun+verb' (OPROV)and verb+object-noun (VONOUN) frames occur with approximately equal frequency in the input. The reliability of the accusative case cue to the patient is slightly higher than that of the verb + noun word order cue to the patient. An additional relevant finding was that the form of the accusative pronoun was that of the third person singular more than $80 \%$ of the time. Thus, this particular case cue is likely to be an easily learnable one. This brings us to our investigation of how patterns of choice in Italian sentence comprehension change during the pre-school years.

\section{STUDY 2}

Children were tested on the three most frequent word orders found in declarative transitives with overt subjects Italian CDS, namely SVONOUN, SOPROV and OPROVS (see (1), (2) and (3)). The cues of animacy, grammatical gender, verbal agreement and verb familiarity were neutralised in our task. This allowed us an unprecedented insight into the extent to which Italian-speaking children rely on local case morphology and syntax in the comprehension of causal action events.

We investigated the five hypothesis outlined above. To recap their predictions were:

H1; Mappability: SVO > (SOPROV, OPROVS $)$

H2: Information-structure: OPROVS $>$ SOPROV

H3: Cue cost / local cues: (SOPROV, OPROVS) > SVO

H4: Cue conflict: (SVO, SOPROV) > OPROVS

H5; Cue collaboration; SOPROV > (SVO, OPROVS)

In addition, as a result of Study 1, we can also add the following cues based on cue reliabiltiies:

H6: Cues to the agent: (SVO, SOPROV) > OPROVS

H7; Cues to the patient: Possibly (SOPROV, OPROVS) > SVO but only very marginally so 


\section{Method}

Participants

There were 24 2;6-year-olds (range $=2 ; 3-2 ; 7,11$ girls), 24 3;6-year-olds (range $=3 ; 5-3 ; 7$, 16 girls) and 24 4;6-year-olds (range $=4 ; 5-4 ; 7,12$ girls,) who participated in the study. All of these children were monolingual speakers of Italian and were tested in a quiet area of their kindergarten in or near Milan, Italy. Eight 2;6-year-olds were tested but excluded from the study due to either showing a side bias during the test trials (4 children), bilingualism (1), experimenter error (1), child refused to complete (1) or child was very distracted right from the beginning (1). A further twelve 3;6-year-olds were tested but excluded due to technical error (5), side bias (5), or bilingualism (2). A further five 4;6year-olds were tested but excluded from the study due to an experimental error (2), side bias (1) or because they had a potential developmental disorder according to parental or kindergarten report (2). We also tested a group of 25 -month-olds but concluded that our task was not suited to this age group since they did not perform above chance in any condition and since a large proportion (7/24) showed a side bias and an additional number simply refused to point on more than half the trials.

\section{Materials}

The three novel actions (which we called chiefare, tammare and baffare) were those used by Dittmar et al. (2008: Exp 3; 2011:1123) and all three referred to prototypical causative-transitive actions, involving direct contact between a volitional agent and an affected patient. Chiefare involved the agent rocking the patient by jumping up and hooking himself onto the patient's back so that the patient rocked back and forth on a kind of rocking-chair/see-saw hybrid object and then fell onto his nose (see the example in Appendix C). Tammare involved the agent jumping onto the patient's head and pushing him down and then releasing him so that he sprang up again (as the patient was standing 
on a kind of disguised jack-in-the-box) until finally the patient fell over. For baffare the patient was standing on the end of a plank. The agent hit the patient, causing the patient to spin around in a circle so that he changed location.

Design

During the session the children sat next to the female native Italian-speaking experimenter in front of a 19" Apple Powerbook laptop screen. For the test trials the child saw two film scenes on the computer screen, each starting simultaneously and lasting six seconds (see Appendix D for an example of how the target and distractor might look before the actions started). Both involved animals enacting the same causal action and differed only in that agent and patient roles were reversed.

All children heard the test sentences for each verb in a 'block'. For each 'block' the order in which the children heard the within-subjects word order conditions (SVONOUNon, SOPROV and OPROVS) was counterbalanced across subjects. For each test trial scene pair we also counterbalanced which particular scene correctly matched the test sentence (e.g. for the pair "dog baff lion" and "lion baff dog" half the children heard the Italian equivalent of "the dog is baffing the lion" and the other half heard the reverse). For this we had an A list and a B list of test sentences (see Appendix B). Nouns which take the feminine article (la) and ended in feminine - a (e.g. la rana 'frog', la mucca 'cow' and la scimmia 'monkey') were always paired together. The same was true for masculines (il gatto 'cat', il cavallo 'horse' and il coniglietto 'bunny') and nouns with the neutral -e ending (il leone 'lion', il maiale 'pig' and il cane 'dog'.

The target screen order was counterbalanced so that each side (left or right) was correct four or five times out of nine trials for each child (depended on counterbalancing order). There were 82 possible orderings for correct side of which 24 were chosen randomly (so that half the children had the 'right' screen as correct 4/9 times and the other half 5/9 times) and these were distributed evenly over the children within each age group. 
We also counterbalanced: the position of the first familiarisation trial and the pairings between particular visual scene items and particular word orders. The direction of the action (from left to right or from right to left) alternated with each trial for each trial. Half the children saw a left-to-right action first. The order of the individual verbs (tammare, baffare and chiefare) was counterbalanced by Latin squares. All of these variables were combined so that the counterbalancing of one did not always coincide with the counterbalancing of another variable. Each child was randomly pre-assigned to one of these orders.

\section{Procedure}

The procedure also mirrored that of Dittmar et al. (2008: Study 3) and was very similar to that used by Dittmar et al. (2011). The experimenter looked at the child's face during the test trial and while she asked the test question until the child responded.

Pointing practice training. To teach the children that the aim of the task was to point to one out of two pictures at a computer screen we used Dittmar et al. (2008: Exp 3)'s warm up task, involving 10 trials, each involving pairs of pictures of objects, such as 'dog' versus 'duck'. The children were asked to point to one of the two objects (e.g., Fammi vedere dov'è ... 'Show me: where is...?'). If a child pointed incorrectly or at both pictures, s/he was given corrective feedback. The child's first responses were scored and the mean scores and ranges for each age group was: 2;6 $(\mathrm{M}=9$, range $=8-10), 3 ; 6(\mathrm{M}$ $=9.9$, range $=9-10), 4 ; 6(\mathrm{M}=9.9$, range $=9-10)$.

Word-learning training. Every novel verb was presented to each child in a live act out. The procedure is that of Dittmar et al. (2008: Exp 3), bar the use of Italian. To the first live act-out for each verb the experimenter used the novel verb in the citation form four times (e.g. (14)). For the second live act-out the experimenter used the verb in three tenses in verb argument structures (e.g. (15), (16) (17) ), whereby only the object pronoun was used. Both animals took feminine gender, so the sentences were completely ambiguous as to who was doing what. 
Film Familiarization trials. Following the live enactment, for each verb the child then saw a familiarization trial in which s/he watched each of the two film scenes (i.e. two videos where the agent and patient roles are reversed) individually and heard the experimenter describing them in the citation form (see (15)) while the other half of the screen remained blank. At the end of each film scene the experimenter pointed to each animal and asked the child "Che cos'è questo?" (What's that?). If a child did not name one of the animals, the experimenter told the child the name and asked him/her to repeat it.

Test Trial. A red dot then centred the child's attention to the middle of the computer screen. Then, the child watched the same two scenes as in the familiarization trials. But here they appeared simultaneously and were accompanied by a pre-recorded linguistic stimulus with the target verb in transitive argument structure (e.g. see e.g. (2), (3) or (4)). After the videos had stopped the experimenter asked the child to point to the correct still picture by asking (19) followed by the past tense form of the linguistic model the child had just heard (e.g. see (20) or (21)). If the child did not point the experimenter repeated the question a second time. Sentence Comprehension Post Test. After all test trials were over the children took part in the 'frase semplice' (= simple sentences) sub-test of the Test di Valutazione del Linguaggio (TVL), livello prescolare (= Test of the Evaluation of Language, Preschool level (Cianchetti \& Sannio Fancello, 1997). In the test the child hears a sentence such as dov'è il bambino che non dorme? (= where is the child that is not sleeping? - see Appendix E for all items and their translation) and has to point to one of four pictures. The parents of the 2;6-year-olds were also asked to complete the Italian version of the MacArthur Communicative Development Inventory (Caselli, \& Casadio, 1995). 13 out of 24 parents did so and all of these children were well within the normal range for word production.

(14) Guard-a che cosa fanno.

Look-IMP that what do;PRS;3PL.

'Look what they are doing!' 
(15)
Questo
si dice
VERB-are.

This

one say;PRS;3SG

VERB-INF.

'That is called VERBing'.

(16) La

VERB-er-à

It;ACC;F;SG

VERB-FUT-3SG

'(It's) gonna verb it'.

(17)

La

VERB-a

$\mathrm{It} ; \mathrm{ACC} ; \mathrm{F} ; \mathrm{SG}$

VERB- PRS;3SG

'(It's) VERBing it.'

(18)
L'
ha
VERB-ato
it;ACC;SG auxiliary;3SG
VERB-PRF

'(It) VERBed it'.

(19) adesso $\mathrm{f}-\mathrm{a}=\mathrm{mmi} \quad$ ved-ere dove /

Now make;IMP;2SG;=ACC1SG see-INF where /

'Show me where /

(20)

$\begin{array}{lllll}1 & \text { ha } & \text { baff-ato } & \text { il } & \text { cane } \\ \text { it;ACC;SG } & \text { auxiliary;3SG } & \text { baff-PRF } & \text { the;M dog }\end{array}$

'The dog baffed him.'

(21) Il

cane

1

ha

baff-ato 
the;M $\quad$ dog $\quad$ it;ACC;SG auxiliary;3SG baff-PRF

The dog baffed him.'

\section{Results}

If the child pointed correctly for a particular trial, this was scored as 1 . If a child pointed incorrectly, this was scored as 0 . Since we were interested in when children begin to comprehend these word orders at above chance level, and since chance for each trial (and over the all trials for a word order condition for the group of 24 children) was 0.5 , if a child pointed to both pictures for a given trial, this was scored as 0.5 . There were some null trials for individual children (4/216 for 2;6-year-olds) which occurred when children did not respond to the second question on a particular trial.. Therefore, the dependent variable was the proportion of correct responses for each word order condition, as shown in Figure 3 .

FIGURE 3 HERE: Mean proportion of correct points (the asterisks mark conditions in which the group performed significantly different from chance)

A 3 (Age Group) x 3 (Word Order Condition) mixed factorial ANOVA found a significant effect for word order $\left(\mathrm{F}(2,138)=4.183, \mathrm{p}=0.017, \eta_{\mathrm{p}}{ }^{2}=.057\right.$, two-tailed $)$ but no main effect for age group $(\mathrm{F}$ $(2,69)=1.008, \mathrm{p}=0.370)$. The interaction between word order $\mathrm{x}$ age group was significant $(\mathrm{F}(4,138)$ $=2.555, \mathrm{p}=0.042, \eta_{\mathrm{p}}{ }^{2}=.069$, two-tailed). We further investigated the interaction with a series of posthoc paired t-tests between the word order conditions with a Bonferroni correction for three comparisons. The 2;6-year-olds performed significantly better with the $S O P R O V$ word order $(\mathrm{M}=$ $69.8 \%$ correct $)$ than with the SVONOUN word order $(\mathrm{M}=49.99 \%$ correct $)(\mathrm{t}(23)=2.984, \mathrm{p}=.007)$. However, no significant difference was found either between SOPROV and OPROVS or between SVONOUN and OPROVS word order for the 2;6-year-olds ( $\mathrm{p}>0.1$ for both comparisons) The 4;6 year-olds pointed correctly significantly more often in the $\operatorname{SVNOUN}(\mathrm{M}=77.78 \%)$ than in the 
OPROVS condition $(\mathrm{M}=54.17 \%)(\mathrm{t}(23)=2.991, \mathrm{p}=.007)$. No difference was found between SOPROV $(66 \%)$ and OPROVS $(\mathrm{p}=.118)$ and a borderline difference was found between the SVONOUN and SOPROV word order for this age group $(\mathrm{p}=0.032)$. Non-parametric (Wilcoxon) tests found the same pattern of results.

We also investigated in which conditions and at which ages the children were above chance (with a Bonferroni correction for three comparisons). The 2;6-year-olds only pointed above chance in the SOPROV condition $(\mathrm{t}(23)=3.930, \mathrm{p}=.001)$. The 3;6-year-olds also pointed above chance in the SOPROV condition $(\mathrm{t}(23)=2.677, \mathrm{p}=.013)$ and they were borderline above chance in the SVONOUN condition $(\mathrm{t}(23)=2.097, \mathrm{p}=.047)$. The 4;6-year-olds pointed above chance in both the SVONOUN $(\mathrm{t}(23)=5.816, \mathrm{p}<.001)$ and the SOPROV conditions $(\mathrm{t}(23)=3.094, \mathrm{p}=.005)$ but like the other age groups they were also at chance in the OPROVS condition $(\mathrm{p}=.53)$.

\section{GENERAL DISCUSSION}

In our first study we carried out the only corpus analysis of Italian CDS to examine the relative word order of subjects and objects with respect to the verb, case marking on pronominal objects, type of referential expression, and the validity of cues to the agent and to the patient in transitive sentences. While it was difficult to differentiate between cues in regards to validity, the cue reliability of word order cues to the agent were quite high ( $76 \%$ for 'first of two arguments' and $83 \%$ for 'noun before verb') and for cues to the patient they were even higher ( $97 \%$ for postverbal nouns and $100 \%$ for accusative case - which a large majority of the time was instantiated by the third person pronouns (see Appendix A). We selected the three most common declarative transitive word orders occurring with overt subjects and used a pointing paradigm to test their comprehension with novel verbs by Italian monolingual children at 2;6, 3;6 and 4;6. We followed the current trend in the field of early argument 
structure comprehension by using no animacy or subject-verb agreement cues and by having the same pairs of characters (e.g. dog and pig) in both the target and foil video clips for each test trial (see e.g. Gertner et al., 2006; Noble et al., 2011; Arunchalam \& Waxman, 2010). We used Dittmar et al.'s (2008) version of this task in which the novel action in the target clip was identical to the novel action in the foil clip. That is, only the semantic roles of e.g. dog and pig were reversed. SOPROV was understood earliest (by 2;6 years). This was followed by SVONOUN order and then OPROVS order. All age groups, even the 4;6-year-olds pointed at chance with the latter word order.

Thus, when taken together with previous studies using a very similar methodology, the current study indicates that the pervasive subject ellipsis in Italian leads to Italian children first comprehending active transitive with two lexical noun phrases at a later age than do German- (e.g. Dittmar et al., 2008), English- (e.g. Dittmar et al., 2011) and even Cantonese-speaking children (e.g. Chan, Lieven \& Tomasello, 2009). Dittmar et al., (2008) found that German 2;6 -year-olds pointed above chance when they heard (case-marked) sentences with two full noun phrases in an identical task, also with novel verbs and also with 9 test trials per child. (In fact, we used essentially an identical task). Englishspeaking children are also capable of pointing above chance with interpreting active transitive when novel verbs at age 2;3 (Noble et al., 2011) and even at 2;1 (Dittmar et al,, 2011

The fact that Italian children are slower to acquire / comprehend NVN = AGENT VERB PATIENT than are German and English children would appear to speak against a universal initial first argument - agent bias (e.g. Bever, 1970; de Villiers \& de Villiers, 1973; and is also problematic for suggestions that children may initially map the first of two arguments onto the agent (although if this heuristic is derived from the input, a la Gertner \& Fisher (2012) then this would be expected for Italian due to pervasive subject ellipsis.). That said, it is entirely possible that Italian one-year-olds follow a first argument $=$ agent bias until they learn the meaning of the accusative pronoun or at least the third person $l o / l a / l$ '/li/le forms. However, if the claim is that children start their acquisition of syntax with a first argument $=$ agent bias, it is difficult to explain why Italian children lag behind their English and 
German counterparts in the acquisition of SVO and why they initially comprehend SOPROV sentences more successfully than SVONOUN sentences.

More importantly, a new finding in relation to previous Competition Model studies (e.g. Bates et al., 1984) is that Italian preschoolers do use morpho-syntactic cues (namely word order and case) in their comprehension of active transitives, even when these contain novel verbs, at least when the morpho-syntactic cues are not having to compete against animacy and subject-verb agreement cues. Italian-speaking children are able to correctly interpret case-marked object pronouns by $2 ; 6$ at the latest (at least when this cue is not competing against the verb-noun cue) and are certainly well above chance at interpreting case-less SVONOUN sentences by 4;6 (and show a tendency towards significance in this by $3 ; 6)$.

In relation to potential hypotheses regarding the order of acquisition of declarative transitive frames with overt subjects, we find that the results of Study 2 can neither be explained in terms of relative 'mappability' (H1) nor in terms of information-structure (H2). Since Study 2, like studies in the previous literature (e.g. Noble et al., 2011; Dittmar et al., 2008), did not use any discourse context and since all event participants on a given trial had the same grammatical gender, the pronominal reference for the SOPROV and OPROVS conditions could only be determined once the reference of the noun had been taken into account. Therefore a mappability account would predict that SVONOUN should be easier to comprehend than SOPROV, which was not the case.

In terms of information structure (H2), both the SOPROV and OPROVS sentences were a little pragmatically odd in the context of our experiment since the pronominal objects had no discourse antecedents. However, since the children were being asked to choose between two clips containing the same action, the sentence subject contains more distinctive information than does the sentence predicate. For this reason, native Italian speakers find the OPROVS condition test sentences (e.g. (20)) more natural than the SOPROV test sentences (see e.g. 21) in the context of this experimental task. 
Yet, all preschool age groups that we tested found the SOPROV sentences easier to comprehend than the OPROVS sentences.

The third potential hypothesis that we investigated related to cue cost or 'local' cues. The prediction (H3) from this view is that the conditions with case-marked pronouns (SOPROV and OPROVS) should be comprehended more easily than the condition in which word order is the only cue to grammatical roles (SVONOUN) (e.g. Ammon \& Slobin, 1979). This view could account for our findings that Italian children initially performed best with SOPROV than with SVONOUN sentences is that the accusative case cue is low in 'cue cost' and is an inherently 'local cue' which can be interpreted 'on the spot'. It might seem surprising that we are arguing this on the basis of evidence from a language like Italian in which case is only available in $45 \%$ of transitive sentences. However, although accusative case is not highly available, as in German, the form-function mappings of case are likely to be easier in Italian than in German, as the nominative/ accusative distinction is always marked on personal pronouns, and the accusative / dative distinction is always marked on the third person singular forms which we used (see Appendix A). Importantly, the third person singular accusative pronouns used in the current experiment show no syncretism within the pronoun system; thus if a child hears $l o, l a$ or $l$ ' occurring directly before an auxiliary or verb, he or she can easily learn that this can only be interpreted as the grammatical object of an Italian sentence. Moreover, if we argue that casemarking in a language with clear form-function mapping is low in cue cost because it can be processed locally and thus focussed on early, we can account for both our current results and findings that Japanese pre-school children seem to perform better on case-marked transitive sentences, even though case-marking is optional and not all that frequent in Japanese (Matsuo, Kita, Shinya, Wood \& Naigles, 2011; Hakuta, 1982).However, if 'cue cost' were the only crucial factor, one would also predict that 'SOPROV' and 'OPROVS' be acquired simultaneously. Instead, even the 4;6-year-olds pointed at chance for 'OPROVS'. 
The poor comprehension of 'OPROVS is, however predicted by H4, the 'cue competition' hypothesis. From our corpus study of CDS it is clear that the two overwhelmingly predominant sentences frames used to express the active transitive in Italian are the 'OPROV' and ' $V O N O U N$ '. These two predominant (subjectless) frames clash headlong with each when the listener hears 'OPROVS' sentences such as (3), (11), (12) and (13).

The other side of the 'competition' coin is collaboration (H5). Dittmar et al. (2008) found not only that OVS / OSV sentences were acquired last, but that case-marked SVO / SOV sentences were acquired / comprehended earlier than non-case-marked SVO /SOV sentences. The relative ease of casemarked SVO / SOV sentences could be due to the fact that these types of sentences give listeners twice the number of morpho-syntactic cues to grammatical roles. That is, word order and case-marking collaborate in indicating the same noun as subject. The 'collaboration' hypothesis (H5) could also account for our finding that the SOPROV sentences were comprehended better by our youngest group of Italian preschoolers than were SVONOUN sentences. That is, in SOPROV sentences the casemarking cue to the patient collaborates with the the word order cue to the agent.

Our hypotheses $\mathrm{H} 6$ and $\mathrm{H} 7$ concerned cue reliabilities and cue validities. These were derived from our corpus study of CDS. We found that all cues for case-marking and word order cues to semantic roles in Italian were more or less equally valid and thus we could not derive any predictions based on cue validity. However, cues to the agent, although all equally low in validity (due to low availability) were differentiable in terms of reliability. The 'first of two arguments' cue was reliable $76 \%$ of the time as a cue to the agent, leading to the prediction that SVONOUN and SOPROV sentences should be comprehended more easily than OPROVS sentences, which was indeed the case. Accusative casemarking was the most reliable cue to the patient, as it was reliable $100 \%$ of the time by definition. This would lead to the prediction that SOPROV and OPROVS sentence frames should be acquired earlier than SVONOUN frames. However, since the VN word order cue was a reliable indicator of the patient 
$97 \%$ of the time, we find a the relative reliability of word order and case cues to the patient a very weak basis for a hypothesis.

\section{CONCLUSIONS}

In sum, our findings show that Italian preschoolers do use morphosyntax to aid their comprehension of transitive sentences. However, their acquisition of SVONOUN word order is delayed in comparison to German and English-speaking children, most probably because the sentential subject is omitted the majority of the time in Italian CDS (see also Serratrice, 2005; Lorusso et al., 2005). Of the three declarative transitive frames tested here, Italian preschoolers comprehended OPROVS sentences worst. This could be accounted for by our hypothesis 4 , cue conflict; this sentence frame contains a conflict between the two most frequent frames used to convey transitive meaning in Italian CDS, namely the OPROV frame and the VONOUN frame. Another (not mutually exclusive) explanation is our hypothesis 6 , cue reliability for the agent. That is, it is statistically far more likely that a subject (if overt) will preceed and not follow the verb in Italian. The fact that the VN cue to the patient is reliable $97 \%$ of the time presumably adds to the difficulties which Italian preschoolers have in comprehending OPROVS. Finally, we found that Italian 2;6 -year-olds find it easier to comprehend SOPROV than SVONOUN sentences. This cannot be accounted for by relative mappability of nouns versus pronouns to referents in the experimental paradigm we adopted (H1), nor can it be accounted for in terms of information-structure (H2), which would actually predict the opposite outcome. Instead, the explanation must derive from the morpho-syntactic properties of Italian. While the relative reliability of cues to the patient are consistent with SOPROV being acquired earlier than SVONOUN, the difference in cue reliability is highly marginal. Both the local cues (H3) and cue collaboration (H5) accounts provide a more plausible account for this order of acquisition. The current study fits in with a body of research which indicates that the relative cue reliability, cue cost, cue conflict and cue collaboration play a very important role in how children learn to map sentence frames onto sentential meaning. We 
thus hope that our study will provide an incentive for future computational studies which might simulate the variation in outcomes in adult processing (and the developmental path towards this) in different languages and might also help define more clearly what is meant by terms such as cue cost. 


\section{REFERENCES}

Ammon, M. \& Slobin, D. (1979). A cross-linguistic study of the processing of causative sentences.

Cognition 7: 3-17. doi:10.1016/0010-0277(79)90007-6

Arunachalam, S. \& Waxman, S. R. (2010). Meaning from syntax: Evidence from 2-year-olds.

Cognition 114, 442-446. (doi: 10.1016/j.cognition.2009.10.015)

Austin, P. (1992). Word order in a free word order language; the case of Jiwarli. La Trobe Papers in Linguistics Vol 5

Bates, E., \& MacWhinney, B. (1982). Functionalist approaches to grammar. In Gleitman, L. \& Wanner, E. (1982). Language acquisition: the state of the art. Cambridge University Press. Pp. $173-218$

Bates, E., \& MacWhinney, B. (1987). Competition, Variation, and Language Learning. In B. MacWhinney (Ed.), Mechanisms of Language Acquisition (pp. 157 - 193). Hillsdale, New Jersey; London: Lawrence Erlbaum.

Bates, E., MacWhinney, B., Caselli, C., Devescovi, A., Natale, F., \& Venza, V. (1984). A crosslinguistic study of the development of sentence interpretation strategies. Child Development, 55(2) 341-354. (doi: 10.2307/1129947)

Bever, T. G. (1970). The cognitive bias for linguistic structures. In J. R. Hayes (Ed.), Cognition and the development of language (pp. 279 - 362). New York: Wiley.

Cameron-Faulkner, T., Lieven, E., \& Tomasello, M. (2003). A construction based analysis of child directed speech. Cognitive Science, 27(6), 843-873.

Caselli, M. \& Casadio, P. (1995). Fondazione “MacArthur” Lo sviluppo communicative nella prima infanzia” Istituto di psicologia CNR Roma

Chan, A., Lieven, E., \& Tomasello, M. (2009). Children's understanding of the agent-patient relations in the transitive construction: Cross-linguistic comparison between Cantonese, German and English. Cognitive Linguistics, 20(2) 267 - 300. (DOI: 10.1515/COGL.2009.015) 
Cianchetti, C. \& Sannio Fancello, G. (1997). Test TVL. Test di valutazione del linguaggio. Livello prescolare. Centro Studi Erickson.

Cipriani, P., Pfanner, P., Chilosi, A., Cittadoni, L., Ciuti, A., Maccari, A., Pantano, N., Pfanner, L., Poli, P., Sarno, S., Bottari, P., Cappelli, G., Colombo, C., \& Veneziano, E. (1989). Protocolli diagnostici e terapeutici nello sviluppo e nella patologia del lin $\neg$ guaggio (1/84 Italian Ministry of Health): Stella Maris Foundation.

D'Amico, S. \& Devescovi, A. (1993). Processi di comprensione dei bambini italiani: i’interpretazione della frase semplice. pp. 273-290. In Guasti, E. \& Moneglia, M. (Eds.). Ricerche sull' acquisizione dell’ italiano. Bulzon: Roma

de Villiers, J. G., \& de Villiers, P. A. (1973). Development of the use of word order in comprehension. Journal of Psycholinguistic Research, 2(4) 331 - 341. DOI: 10.1007/BF01067055

Devescovi, A., D'Amico, S., \& Gentile, P. (1999). The development of sentence comprehension in Italian: A reaction time study. First Language 19, 129 - 163. (DOI: $10.1177 / 014272379901905601)$

Dittmar, M., Abbot-Smith, K., Lieven, E.V.M., \& Tomasello, M. (2008). German children's comprehension of word order and case marking in causative sentences. Child Development 79(4), 1152-1167. (DOI: 10.1111/j.1467-8624.2008.01181.x)

Dittmar, M., Abbot-Smith, K., Lieven, E.V.M., \& Tomasello, M. (2011) 2;1-year-olds use transitive syntax to make a semantic-role interpretation in a pointing task. Journal of Child Language 38(5): 1109-1123 (doi:10.1017/S0305000910000747)

DuBois, J. (1987). The discourse basis of ergativity. Language, 63: 805-855.Frascarelli, M. (2000). The syntax-phonology interface in focus and topic constructions in Italian. Dordrecht: Kluwer Academic Publishers 
Gertner, Y., Fisher, C., \& Eisengart, J. (2006). Learning words and rules: Abstract knowledge of word order in early sentence comprehension. Psychological Science 17(8), 684-691. (doi:

10.1111/j.1467-9280.2006.01767.x)

Gertner, Y., \& Fisher, C. (2012). Predicted errors in early verb learning. Cognition 124: 85-94 (http://dx.doi.org/10.1016/j.cognition.2012.03.010)

Göksun, T., Küntay, A. \& Naigles, L. (2008). Turkish children use morphosyntactic bootstrapping in interpreting verb meaning. Journal of Child Language 35: 291-323. (http://dx.doi.org/10.1017/S0305000907008471)

Kempe, V., \& MacWhinney, B. (1999). Processing of morphological and semantic cues in Russian and German. Language and Cognitive Processes 14(2), 129-171 (DOI: 10.1080/016909699386329)

Lindner, K. (2003). The development of sentence-interpretation strategies in monolingual Germanlearning children with and without specific language impairment. Linguistics 41(2), 213-254.

Lorusso, P., Caprin C. \& Guasti, M. (2005). Overt subject distribution in early Italian children. In Brugos, A. Clark-Cotton, M. \& Ha, S. (Eds.). A supplement to the proceedings of the $29^{\text {th }}$ annual Boston University Conference on Language Development.

MacWhinney, B. (2000). The CHILDES project: Tools for analyzing talk (3rd ed.). Mahwah, NJ: Lawrence Erlbaum Associates.

MacWhinney, B., Bates, E., \& Kliegl, R. (1984). Cue validity and sentence interpretation in English, German and Italian. Journal of Verbal Learning and Verbal Behavior 23, 127-150. (http://dx.doi.org/10.1016/S0022-5371(84)90093-8)

Matessa, M., \& Anderson, J. R. (2000). Modelling focused learning in role assignment. Language and Cognitive Processes 15(3), 263-292. (DOI: 10.1080/016909600386057)

McDonald, J. L., \& MacWhinney, B. J. (1995). The time course of anaphor resolution: Effects of implicit verb causality and gender. Journal of Memory and Language 34, 543-566. (http://dx.doi.org/10.1006/jmla.1995.1025) 
Matsuo, A., Kita, S., Shinya, Y., Wood, G. \& Naigles, L. (2012). Japanese two-year-olds use morphosyntax to learn verb meanings. Journal of Child Language 39(3): 637-663. (doi:10.1017/S0305000911000213)

Mintz, T. (2003). Frequent frames as a cue for grammatical categories in child-directed speech. Cognition 90: 91-117. doi:10.1016/S0010-0277(03)00140-9

Naigles, L., Reynolds, C. \& Kuntay, A. (2011), 2- and 3-year-olds' sensitivity to pronoun case in English sentence comprehension. Proceedings of the $35^{\text {th }}$ Annual Boston University Conference on Child Language. Somerville, MA: Cascadilla Press..

Noble, C., Rowland, C., \& Pine, J. (2011). Comprehension of argument structure and semantic roles: Evidence from English-learning children and the forced-choice pointing paradigm. Cognitive Science 35(5), 963-982. (DOI: 10.1111/j.1551-6709.2011.01175.x)

Pinto, M. (1997). Licensing and interpretation of inverted subjects in Italian. UiLOTS Dissertation Series.

Slobin, D. I. (1982). Universal and particular in the acquisition of language. In L. R. Gleitman \& E. Wanner (Eds.), Language acquisition: The state of the art (pp. 128-170). Cambridge: Cambridge University Press.

Slobin, D. I., \& Bever, T. G. (1982). Children use canonical sentence schemas: A crosslinguistic study of word order and inflections. Cognition 12, 229-265. (http://dx.doi.org/10.1016/0010$\underline{0277(82) 90033-6,)}$

Sokolov, J. L. (1988). Cue validity in Hebrew sentence comprehension. Journal of Child Language, 15, $129-155$.

Tomasello, M., \& Akthar, N. (1995). Two-year-olds use pragmatic cues to differentiate reference to objects and actions. Cognitive Development, 10: 201-224.

Tonelli, L., \& Fabris, M. (2005). L’acquisizione della flessione verbale - Esemplificazione di un metodo di ricerca. AnnalSS 2, 13-34. 
Wells, C. G. (1981). Learning through interaction: The study of language development . Cambridge: CambridgeUniversity Press. 


\section{APPENDICES}

Appendix A: Italian pronouns

\begin{tabular}{|c|c|c|c|c|c|}
\hline Nominative & $\begin{array}{l}\text { (English } \\
\text { translation) }\end{array}$ & Accusative & $\begin{array}{l}\text { (English } \\
\text { translation) }\end{array}$ & Dative & $\begin{array}{l}\text { (English } \\
\text { translation) }\end{array}$ \\
\hline io & I & Mi & me & Mi & me \\
\hline tu & $\begin{array}{l}\text { You } \\
\text { (informal) }\end{array}$ & $\mathbf{T i}$ & you & $\mathbf{T i}$ & you \\
\hline lui & $\begin{array}{l}\text { He / It for } \\
\text { masc object }\end{array}$ & Lo (or l') & him & Gli & him \\
\hline lei & $\begin{array}{l}\text { She / It for } \\
\text { fem objects }\end{array}$ & La (or l') & her & le & her \\
\hline Lei & You (formal) & $\mathbf{L a}$ & you & & you \\
\hline noi & We & $\mathbf{C i}$ & us & $\mathbf{C i}$ & us \\
\hline voi & $\begin{array}{l}\text { You } \\
\text { (informal, } \\
\text { plural) }\end{array}$ & $\mathbf{V i}$ & you & $\mathbf{V i}$ & you \\
\hline loro & They & li & Them (masc) & Gli & them \\
\hline & & le & Them (fem) & Gli & them \\
\hline
\end{tabular}




\section{Appendix B}

Example sentences pointing experiment (study 2)

(For this sub-set half of the children heard the sentences with reversed agent and patient)

\begin{tabular}{|l|l|l|l|}
\hline & Word order condition & Test sentence & Approximate translation \\
\hline Set B1 & SVONOUN & il coniglietto tamma il cavallo & The bunny is tamming the horse \\
\hline & & La scimmia baffa la rana & The monkey is baffing the frog \\
\hline & S OP $+V$ & Il maiale chiefa il leone & The pig is chiefing the lion \\
\hline & & Il gatto lo chiefa & The cat is chiefing him \\
\hline & & La mucca la tamma & The cow is tamming him \\
\hline & & lo baffa il cavallo & The lion is baffing him \\
\hline & & la chiefa la rana & it's him that the horse is baffing \\
\hline & & lo tamma il cane & It's him that the frog is chiefing \\
\hline
\end{tabular}

\begin{tabular}{|l|l|l|l|}
\hline Set B2 & SVONOUN & Il gatto chiefa il conigiletto & The cat is chiefing the bunny \\
\hline & & La mucca tamma la scimmia & The cow is tamming the monkey \\
\hline & Il leone baffa il cane & The lion is baffing the dog \\
\hline & & Il cane lo tamma & The dog is tamming him \\
\hline & & Il cavallo lo baffa & The horse is baffing him \\
\hline & LP $+V S$ & lo tamma il coniglietto & The frog chiefing him \\
\hline & & la baffa la scimmia & It's him that the bunny is tamming \\
\hline & & lo chiefa il maiale & It's him that the monkey is baffing \\
\hline
\end{tabular}

\begin{tabular}{|l|l|l|l|}
\hline Set B3 & SVONOUN & Il cavallo baffa il gatto & The horse is baffing the cat \\
\hline & & La rana chiefa la mucca & the frog is chiefing the cow \\
\hline & Il cane tamma il maiale & The dog is tamming the pig \\
\hline & & La scimmia la baffa & The monkey is baffing him \\
\hline & & Il maiale lo chiefa & The pig is chiefing him \\
\hline & OP+VS & il coniglietto lo tamma & The bunny is tamming him \\
\hline & & lo chiefa il gatto & It's him that the cat is chiefing \\
\hline & & lo baffa il leone & It's him that the cow is tamming \\
\hline
\end{tabular}


Appendix C: Example novel action (chiefare) as it appears before during and after action on one side of the screen

1.

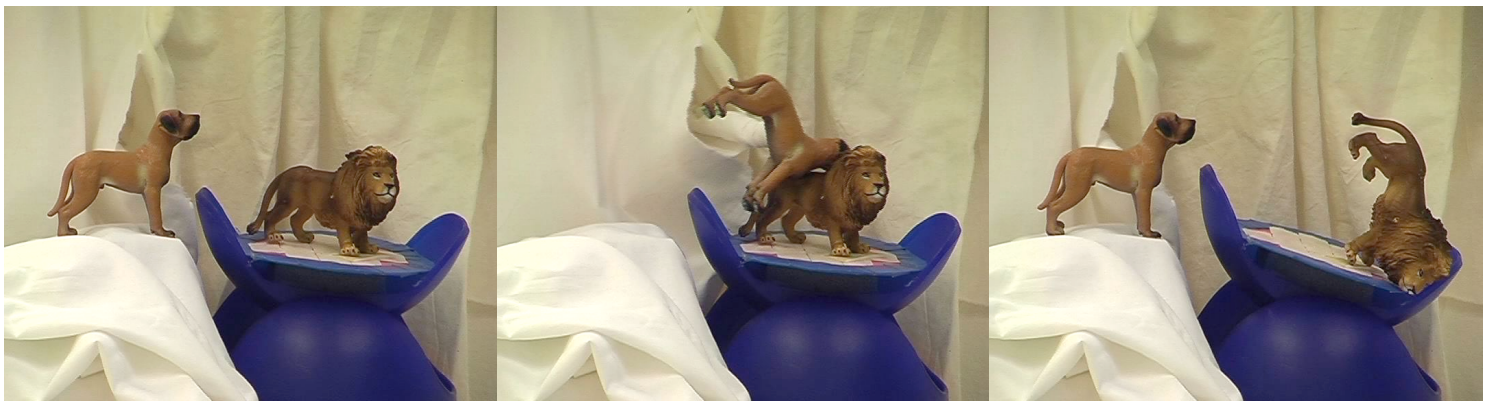


Appendix D: Example target and distractor screens (chiefare) before the start of the action

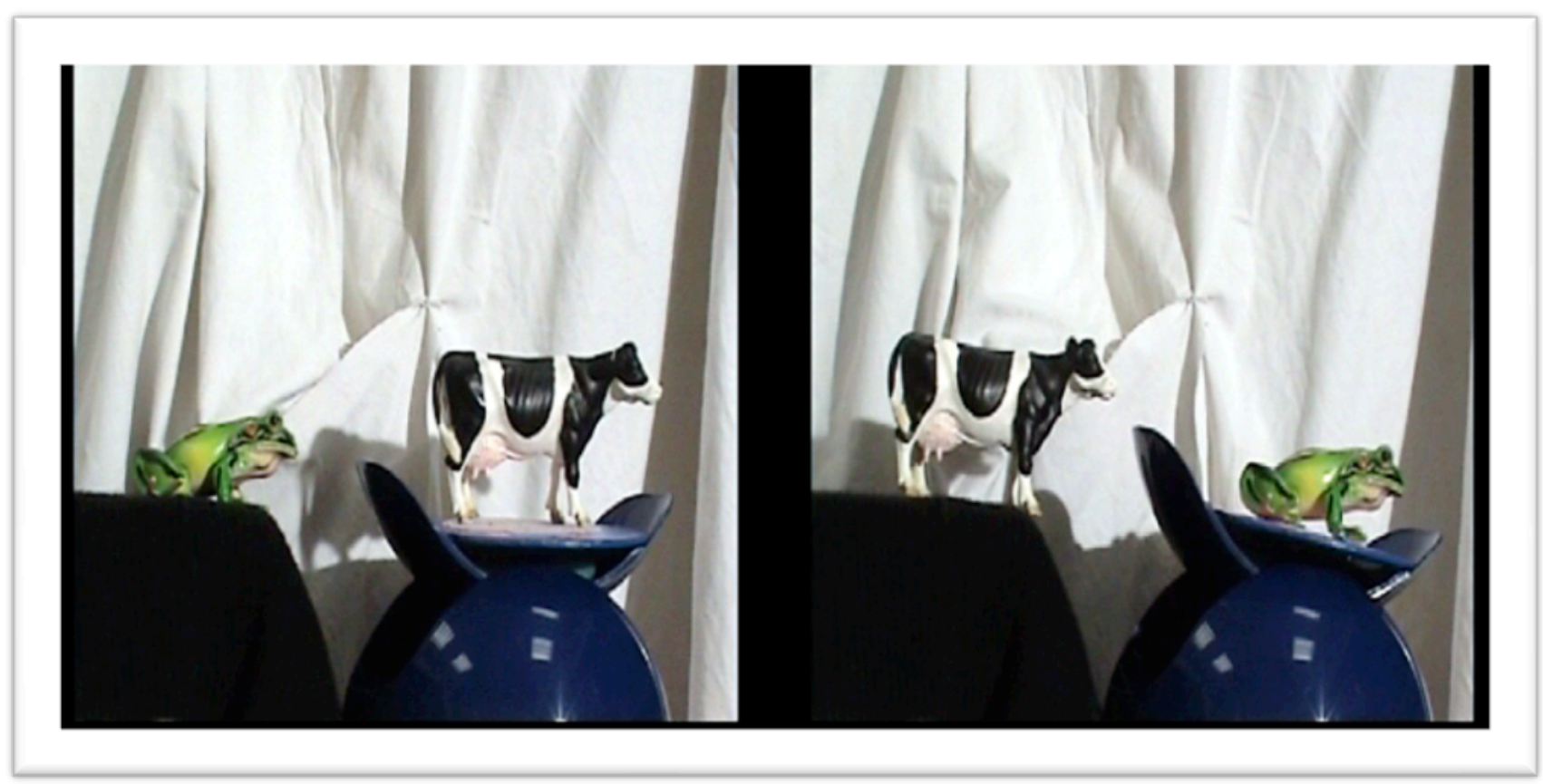




\section{Appendix E: Standardised language comprehension post-test (Frase semplice)}

Fammi vedere...... (= Show me.....).

2. Il bambino che corre (the boy who is running)

3. Il bambino che disegna (the boy who is drawing)

4. La bambina che si lava (the girl who is washing herself)

5. L'uomo che pesca (the man who is fishing)

6. Il bambino che legge (the boy who is reading)

7. La bambina che si lava i denti (the girl who is brushing her teeth)

8. La bambina che mangia la banana (the girl who is eating a banana)

9. Il bambino che strappa il giornale (the boy who is tearing up the newspaper)

10. L'uomo che misura il muro (the man who is measuring the wall)

11. La bambina che pettina la bambola (the girl who is combing the doll)

12. La bambina che non stira (the girl who is not ironing)

13. La bambina che non disegna (the girl who is not drawing)

14. Il bambino che non rompe il piatto (the boy who is not breaking a plate)

15. Il bambino che non dorme (the boy who is not sleeping)

16. Il bambino che non gioca a palla (the boy is not playing football) 
TABLES

Table 1: Details of the Italian child-directed maternal speech corpora

\begin{tabular}{|l|l|l|l|l|l|l|l|}
\hline Corpus & Child & $\begin{array}{l}\text { Age } \\
1^{\text {st }} \\
\text { recor } \\
\text { ded }\end{array}$ & $\begin{array}{l}\text { Age } \\
\text { Last } \\
\text { recorded }\end{array}$ & $\begin{array}{l}\text { No. } \\
\text { recordings }\end{array}$ & $\begin{array}{l}\text { Recordings } \\
\text { analysed }\end{array}$ & $\begin{array}{l}\text { Total } \\
\text { maternal } \\
\text { utterances } \\
\text { examined }\end{array}$ & $\begin{array}{l}\text { Total } \\
\text { declarative } \\
\text { transitive } \\
\text { utterances }\end{array}$ \\
\hline Tonelli & Marco & $1 ; 5$ & $2 ; 5$ & 27 & 27 & 14965 & 1311 \\
\hline & Elisa & $1 ; 10$ & $2 ; 1$ & 8 & 8 & 721 & 109 \\
\hline & Gregorio & $1 ; 7$ & $2 ; 0$ & 8 & 8 & 1048 & 67 \\
\hline Calambrone & Diana & $1 ; 8$ & $2 ; 6$ & 9 & 9 & 948 & 47 \\
\hline & Guglielmo & $2 ; 2$ & $2 ; 11$ & 9 & $\begin{array}{l}\text { Samples } \\
\text { of } 4\end{array}$ & See text & 16 \\
\hline & Martina & $1 ; 7$ & $2 ; 7$ & 13 & $\begin{array}{l}\text { Samples } \\
\text { of } 4\end{array}$ & See text & 17 \\
\hline & Raffaello & $1 ; 7$ & $2 ; 11$ & 17 & $\begin{array}{l}\text { Samples } \\
\text { of } 4\end{array}$ & See text & 21 \\
\hline & Rosa & $1 ; 7$ & $3 ; 3$ & 21 & $\begin{array}{l}\text { Samples } \\
\text { of } 4\end{array}$ & See text & 12 \\
\hline & Viola & $1 ; 11$ & $2 ; 10$ & 10 & $\begin{array}{l}\text { Samples } \\
\text { of } 4\end{array}$ & See text & 24 \\
\hline
\end{tabular}

Table 2: Formal characteristics of declarative transitive utterances by mother

\begin{tabular}{|l|l|l|l|l|l|l|l|l|l|l|l|}
\hline $\begin{array}{l}\text { Mother } \\
\text { of.... }\end{array}$ & $\begin{array}{l}\text { Total } \\
\text { decl } \\
\text { trans }\end{array}$ & $\begin{array}{l}\text { Total } \\
\text { transitive } \\
+ \text { overt } \\
\text { subjects }\end{array}$ & $\begin{array}{l}\text { Total } \\
\text { SVO }\end{array}$ & $\begin{array}{l}\text { Total } \\
\text { SOV }\end{array}$ & $\begin{array}{l}\text { Total } \\
\text { OVS }\end{array}$ & $\begin{array}{l}\text { Total } \\
\text { VSO }\end{array}$ & $\begin{array}{l}\text { Total } \\
\text { VOS }\end{array}$ & $\begin{array}{l}\text { Total } \\
\text { OVSO }\end{array}$ & $\begin{array}{l}\text { V+ } \\
\text { Objec } \\
\text { Noun } \\
\text { VO } \\
\text { NOU } \\
\text { N) }\end{array}$ & $\begin{array}{l}\text { Obj } \\
\text { pron+ } \\
\text { Verb } \\
\text { (OPR } \\
\text { OV) }\end{array}$ & $\begin{array}{l}\text { Total } \\
\text { decl } \\
\text { transitive } \\
\text { that were } \\
\text { causative }\end{array}$ \\
\hline Marco & 1311 & 317 & 167 & 69 & 41 & 9 & 31 & 0 & 481 & 387 & 742 \\
\hline Elisa & 109 & 33 & 21 & 5 & 3 & 1 & 2 & 1 & 42 & 28 & 59 \\
\hline Gregorio & 65 & 7 & 4 & 1 & 2 & 0 & 0 & 0 & 27 & 25 & 49 \\
\hline Diana & 47 & 4 & 1 & 0 & 3 & 0 & 0 & 0 & 13 & 25 & 22 \\
\hline Guglielmo & 16 & 1 & 1 & 0 & 0 & 0 & 0 & 0 & 9 & 5 & 10 \\
\hline Martina & 17 & 4 & 3 & 1 & 0 & 0 & 0 & 0 & 8 & 5 & 11 \\
\hline Raffaello & 21 & 4 & 2 & 2 & 0 & 0 & 0 & 0 & 4 & 13 & 7 \\
\hline Rosa & 12 & 2 & 0 & 2 & 0 & 0 & 0 & 0 & 1 & 5 & 7 \\
\hline Viola & 24 & 4 & 1 & 0 & 2 & 1 & 0 & 0 & 6 & 13 & 15 \\
\hline
\end{tabular}




\section{FIGURES}

Figure 1: Word order and case cue validities for cues for the patient (not taking type of referring expression into account).

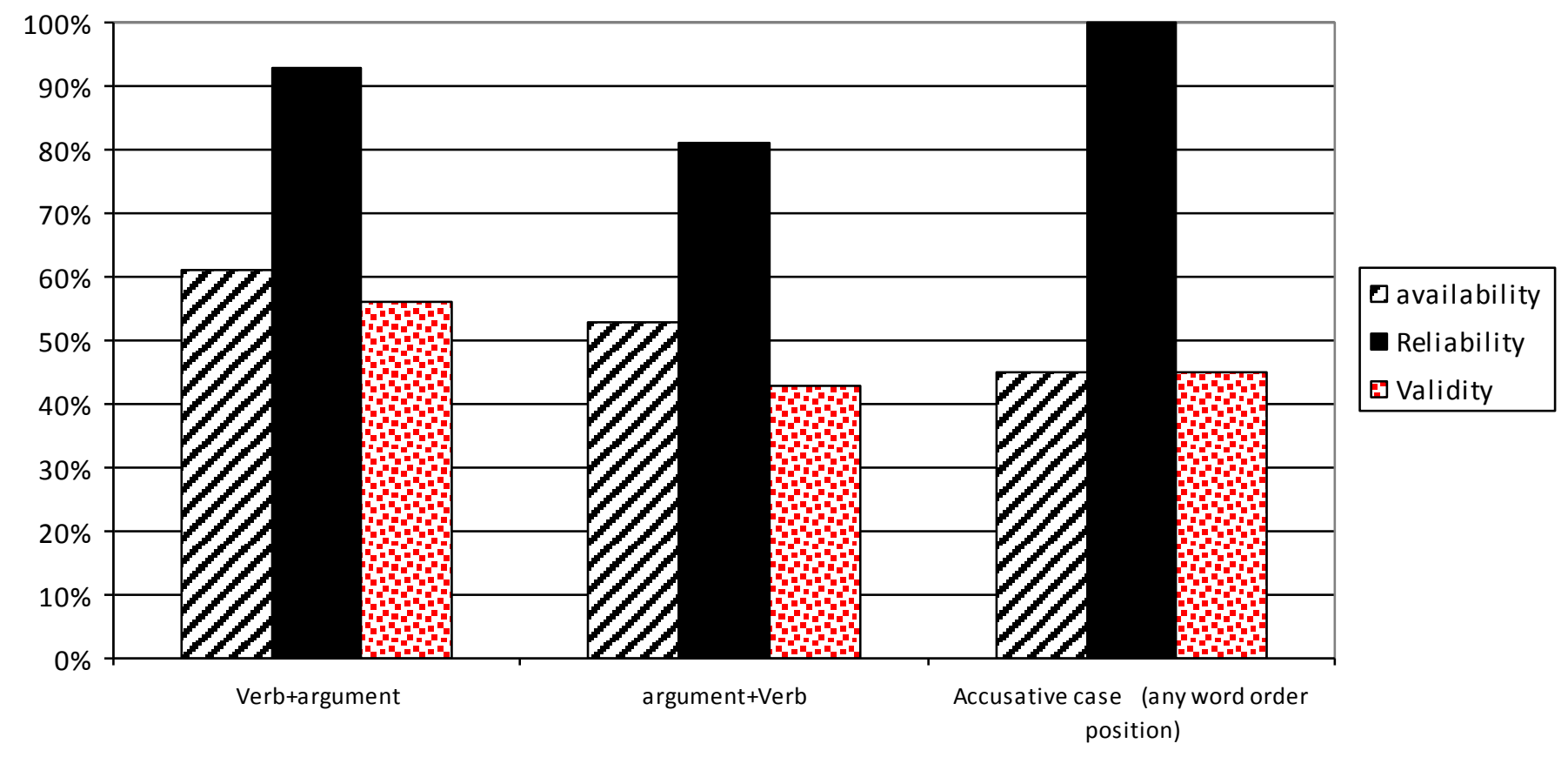


Figure 2: Slot and frame type cue validities.

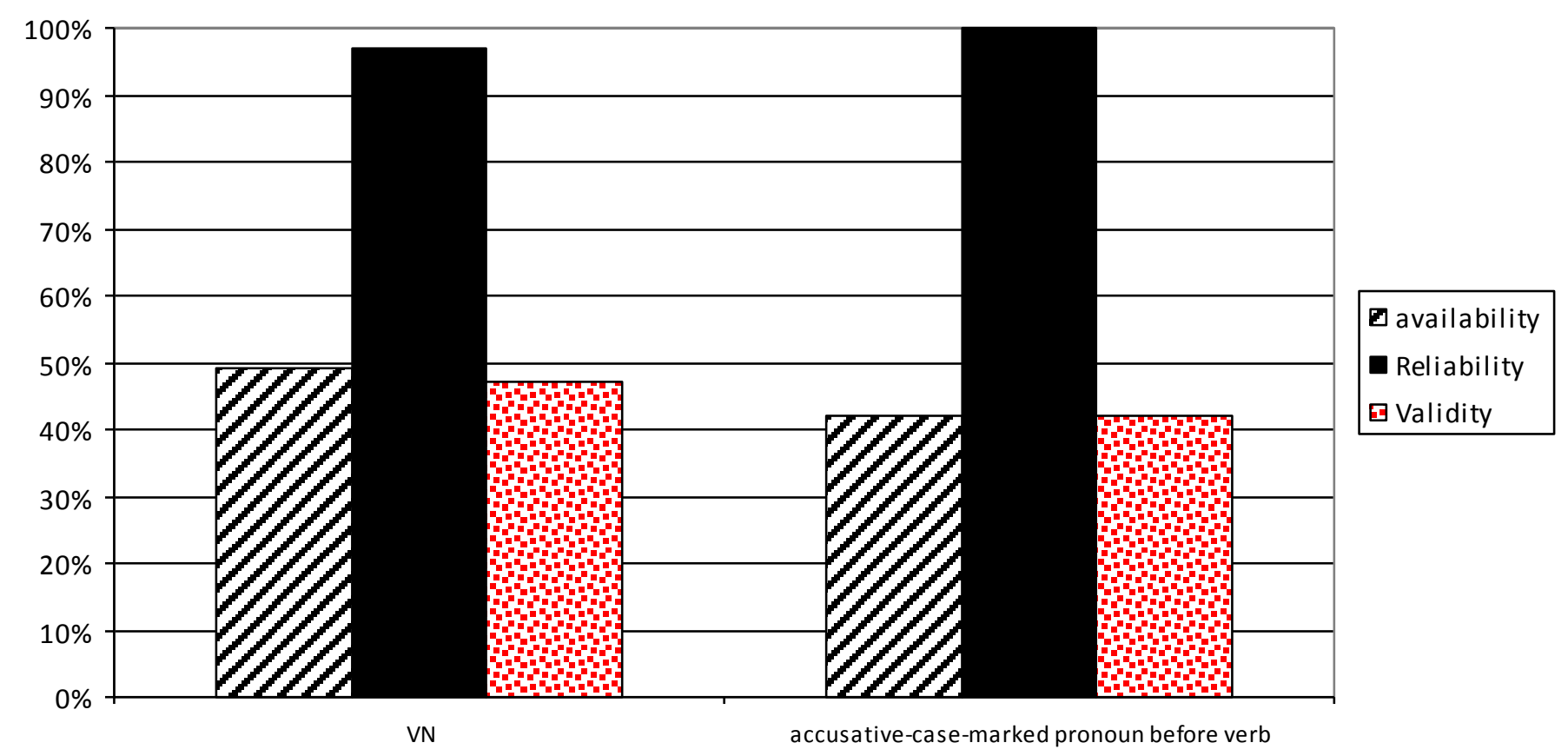


Figure 3: Mean proportion of correct points (the asterisks mark conditions in which the group performed significantly different from chance)

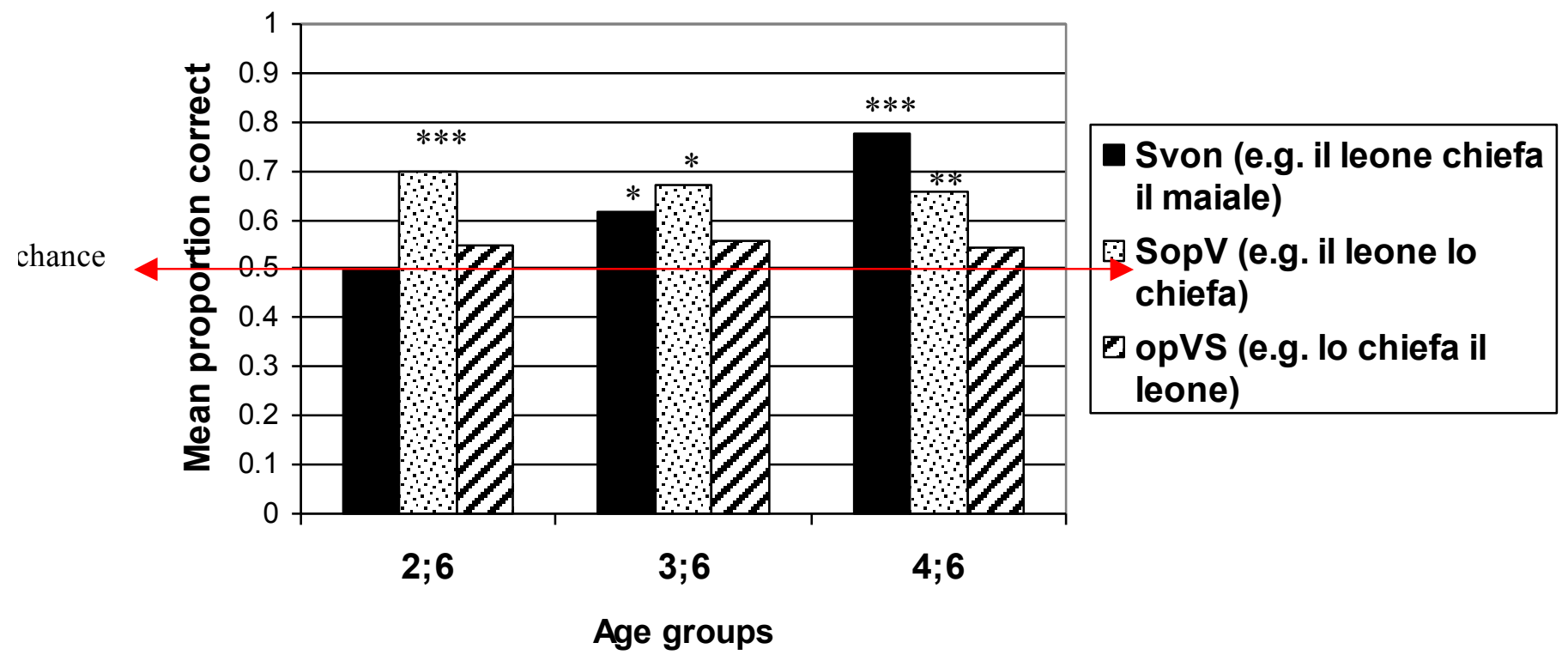

